\title{
A pontuação na escrita de alunos do sexto ano do ensino fundamental
}

DOI: http://dx.doi.org/10.21165/el.v50i1.3019

\author{
Marian Oliveira' \\ Noélia Nascimento Ferraz Amorim²
}

\section{Resumo}

Neste artigo apresentamos os resultados obtidos com a implementação de uma proposta de intervenção pedagógica, que visou analisar se um ensino pautado em reflexões linguísticas acerca do uso dos sinais de pontuação, enquanto marcadores prosódicos e indicadores semânticos, contribuiria para que alunos do $6^{\circ}$ ano do Ensino Fundamental pontuassem corretamente suas produções e reconhecessem o papel desses marcadores gráficos de pontuação na escrita e na leitura. Trata-se de uma pesquisa aplicada, de natureza quali-quantitativa, desenvolvida no âmbito do ProfLetras, que envolveu alunos de uma escola pública de Vitória da Conquista, Bahia. Os resultados apontam uma melhora no nível de aprendizagem que pode ser verificada pelo aumento no índice de reconhecimento, entendimento das diferentes funções e emprego dos sinais de pontuação.

Palavras-chave: ensino fundamental; intervenção pedagógica; pontuação; ProfLetras.

1 Universidade Estadual do Sudoeste da Bahia (UESB), Candeias, Bahia, Brasil; marian.oliveira@uesb.edu.br; https://orcid.org/0000-0002-8243-152X

2 Universidade Estadual do Sudoeste da Bahia (UESB), Candeias, Bahia, Brasil; noeliaferraz@hotmail.com; http://orcid.org/0000-0002-8168-1981 


\title{
The punctuation in the writing of the students of the elementary education
}

\begin{abstract}
In this paper, we show the results obtained in the pedagogical intervention proposal, about punctuation, that was applied to $6^{\text {th }}$-grade elementary school students of a public school at Vitória da Conquista, Bahia. The objective was to verify if a teaching method about punctuation use that has based on linguistic reflections and that considered the punctuation like prosodics marks and semantic indicators could contribute to learning and a correct application of these graphic marks in texts written by students. The results point to an improvement in the learning levels. This can be verified from the following data: increase in the index of recognition of punctuation marks and understanding of the different functions and correct use of these graphic signs by the learners in your texts. At the end of the pedagogical intervention, the students demonstrated an understanding of the relationship between punctuation marks and punctuation and intonation.
\end{abstract}

Keywords: elementary school; pedagogical intervention; punctuation marks; ProfLetras.

\section{Introdução}

Não seria um exagero dizer que muitos alunos concluem o ensino básico apresentando marcada dificuldade no domínio da leitura e da escrita. Essa pouca habilidade do aluno com a leitura e a escrita tem sido constatada também pelos mecanismos de avaliação do Estado, sejam eles nacionais: Avaliação Nacional do Rendimento Escolar (ANRESC) ou internacionais: Programa Internacional de Avaliação de Alunos (PISA), realizado pela Organização para Cooperação e Desenvolvimento Econômico (OCDE). Muitas vezes, tal dificuldade está relacionada a um parco conhecimento sobre pontuação, adquirido por meio de um ensino pouco significativo, focado na apresentação de frases isoladas, explicações pouco consistentes, as quais defendem que a pontuação indica quando devemos respirar e que não consideram que, além de a pontuação denotar aspectos prosódicos da fala, também é importante para a construção de sentido do texto, contribuindo para a sua clareza.

Neste artigo, apresentamos os resultados obtidos com a implementação de uma proposta de intervenção, cujo objetivo foi mostrar que um ensino pautado em reflexões linguísticas acerca do uso dos sinais de pontuação, enquanto marcadores prosódicos e indicadores semânticos, concorreria para que alunos do $6^{\circ}$ ano do Ensino Fundamental pontuassem corretamente suas produções e reconhecessem o papel desses marcadores gráficos de pontuação na escrita e na leitura. A pesquisa, de natureza quali-quantitativa, foi desenvolvida numa escola pública de Vitória da Conquista, Bahia, com alunos do $6^{\circ}$ ano que, após aplicação de atividade diagnóstica, por meio de sorteio, foram divididos entre Grupo Controle (GC) e Grupo Teste (GT), sendo este último submetido a uma intervenção 
pedagógica, cujas atividades foram centradas na pontuação como marcador prosódico da escrita e sua relevância para o estabelecimento de sentido do texto.

O estudo está embasado nas propostas de Cagliari $(1989,1999)$, Chacon (1996) e Pacheco $(2003,2006)$; também toma como base duas pesquisas sobre o tema - Oliveira (2015) e Alves (2016) - realizadas no âmbito do ProfLetras. Salientamos que, para uma pesquisa dessa natureza, necessário se faz considerar os manuais de gramática, bem como as orientações dos Parâmetros Curriculares Nacionais (1998) e a Base Nacional Comum Curricular (2018). Elaboramos uma Proposta de Intervenção Pedagógica como forma de confrontar as propostas linguísticas com a nossa própria prática docente, muitas vezes orientada por esses manuais.

Em relação à estrutura, este artigo está organizado em quatro seções, além dessa introdução: na primeira, apresentamos, brevemente, as diferentes perspectivas sobre a pontuação; na segunda, discorremos acerca dos procedimentos metodológicos adotados, o campo de estudo, os participantes da pesquisa e o detalhamento das etapas da Proposta de Intervenção Pedagógica; na terceira, apresentamos os dados resultantes da implementação da proposta de intervenção e analisamos os resultados das Atividades Diagnóstica e Final, alcançados pelos dois grupos de alunos participantes da pesquisa - o GT e o GC -, contrastando os índices alcançados pelos dois grupos antes e depois da implementação da sequência de atividades da Proposta Pedagógica e discutindo os efeitos decorrentes da aplicação dessas atividades. Por fim, apresentamos as conclusões gerais desta pesquisa, retomando os pontos mais relevantes no desenvolvimento do trabalho, sinalizando para os seus avanços e desafios. Assim, acreditamos poder contribuir com o fazer pedagógico, de outros professores de Língua Portuguesa, acerca do ensino dos sinais de pontuação.

\section{Breve apanhado sobre pontuação}

Em sua prática, para falar de pontuação, em geral, o professor lança mão dos estudos gramaticais, que se configuram como instrumentos de ensino nas salas de aula e alimentam os livros didáticos, cuja abordagem sobre o tema "pontuação" se dá de forma bastante superficial e resumida. Salientamos que o trabalho do professor, baseado apenas nesses conceitos gramaticais tradicionais (listagem de regras), não tem surtido o efeito esperado, posto que observamos em nossa prática docente que os discentes, ou grande parte deles, concluem o Ensino Fundamental sem ter adquirido, dentre outros, o domínio necessário para usarem adequadamente os sinais de pontuação. Assim sendo, para dar conta do nosso objeto de estudo, a saber, ensino dos sinais de pontuação, como elementos da escrita que recuperam marcadores prosódicos da fala e que concorrem para a construção/atribuição de sentido do texto, apresentamos os subsídios teóricos que subjazem aos conceitos gramaticais, pois acreditamos que o ensino pautado nos estudos linguísticos pode gerar um aprendizado mais eficaz, visto que toma como base os usos reais da língua. 


\section{Sinais de pontuação sob a perspectiva dos estudos em prosódia}

Embora não se possa admitir uma relação simétrica entre a prosódia da fala e a pontuação na escrita, pois isso nos obrigaria a admitir a transferência total de padrões orais para a escrita, que tem, na pontuação, como observa Chacon (1996), a marcação do seu próprio ritmo, não se pode deixar de reconhecer que a pontuação recupera nuances da fala e que isso confere ao texto escrito o ritmo da linguagem geral. Vários estudos nesse sentido já foram desenvolvidos. Apresentaremos, a seguir, a perspectiva de alguns deles. Nessa abordagem, atentar-nos-emos às questões referentes às definições e aos usos/funções dos sinais de pontuação, cujo entendimento consideramos relevante para a explicação dos dados analisados.

De acordo com Cagliari (1999), a temática que envolve os sinais de pontuação é pouco explorada pelos linguistas. Segundo o autor, "há tanta divergência nesta área que os autores nem sequer concordam com o conjunto de marcas que devem ser entendidas como sinais de pontuação" (CAGLIARI, 1999, p. 197), havendo, portanto, necessidade de mais estudos sobre esse fenômeno.

Cagliari (1989) define os sinais de pontuação como sendo recursos sinalizadores de "padrões entoacionais", ou seja, representam, na escrita, ocorrências da fala, tais como, asserção, pergunta, dúvida, admiração, dentre outros. Além de associar cada sinal de pontuação a um tom, Cagliari (1989) afırma que é possível "combinar esses sinais", gerando tons diferentes.

Com base nas funções que cada sinal de pontuação pode desempenhar, Cagliari (1999, p. 198) propõe uma classificação destes em cinco grupos, a saber: a) sintáticos ${ }^{3}$ - delimitam classes e unidade sintáticas; b) sinais semântico-discursivos - delimitam os limites de unidades que abrangem além da frase; c) sinais prosódicos - orientam as unidades prosódicas (tom, entoação, pausa); d) sinais sinalizadores - sinalizam um deslocamento do texto para outro local onde se encontra o complemento da leitura e; e) sinais tipográficos - dão suporte à leitura.

Apesar de fazer essa distinção entre os sinais de pontuação considerando a função que cada um pode exercer, Cagliari (1999) ressalta que esta classificação não é estática; um mesmo sinal pode exercer mais de uma função, podendo se encaixar em mais de uma das classificações supracitadas.

Os sinais de pontuação trazem para o enunciado indicações de diferentes variações melódicas que concorrem para a orientação do leitor no ato efetivo de leitura. Assim,

3 A nomenclatura das classes dos sinais de pontuação aparece em itálico na obra do autor. 
o leitor que, mesmo lendo em silêncio, "precisa decifrar a escrita" (CAGLIARI, 1989, p. 202), necessita incluir nessa atividade a percepção dos sinais de pontuação por meio dos quais as entoações podem ser representadas.

Por sua vez, Chacon (1996) destaca que os sinais de pontuação figuram como marcas exclusivas da escrita, pois só se apresentam materializados de forma gráfico-visual e aparecem apenas nas práticas de linguagem que se utilizam da escrita. Além disso, o autor nos chama a atenção para o fato de os sinais de pontuação possuírem natureza linguística, uma vez que estes sinais, ao exercerem sua função delimitativa sobre determinada estrutura, o fazem envolvendo tanto a dimensão fônica quanto a dimensão semântica dessas estruturas.

A utilização dos sinais de pontuação é polissêmica, pois não há "um vínculo constante entre as marcas gráficas e as funções semânticas a elas associadas" (CHACON, 1996, p. 123) e, ainda, porque essas marcas são empregadas de formas diferentes na delimitação de estruturas linguísticas. Ademais, esses sinais apresentam como característica a capacidade de recuperar/demarcar "na escrita aspectos rítmicos que são vistos como mais característicos da oralidade." (CHACON, 1996, p. 128-129).

Conforme os estudos de Pacheco (2006), os sinais de pontuação se constituem como marcas gráficas que indicam variações prosódicas na escrita, ou seja, determinam de que forma o leitor deverá se comportar prosodicamente. Pacheco (2006, p. 88), baseando-se em Cagliari (1989), considera que os sinais de pontuação, ao lado de outros recursos gráficos ${ }^{4}$, figuram como marcadores prosódicos: "recursos que expressam informações de caráter estritamente prosódico que são típicos da fala oral, em situações comunicativas.".

Ainda de acordo com Pacheco (2006), os sinais de pontuação apresentam sentidos convencionais que são de natureza prosódica. Dessa forma, a presença desses sinais "em um texto escrito acena para o leitor que o enunciado sob o seu escopo deverá ter um padrão prosódico particular" (PACHECO, 2006, p. 155), ou seja, durante a realização de uma leitura oral será possível perceber algumas variações decorrentes da oralização de um determinado sinal de pontuação.

Assim, entendemos que, se a leitura e a escrita de um texto não se limitam à codificação/ decodificação de palavras, faz-se necessário queo ensino/aprendizado da pontuaçãolance mão de noções que considerem que a pontuação organiza sintática e semanticamente o texto escrito de forma que este tenha clareza e facilite o entendimento do leitor. Por

4 De acordo com a autora, endossando os pressupostos de Cagliari (1999), são considerados marcadores prosódicos: tipo e tamanho de letra, paragrafação, transcrição fonética, referências ao modo de dizer e sinais de pontuação. Nos deteremos apenas nesse último. 
outro lado, não podemos esquecer que, ao produzir um texto escrito, precisamos levar em consideração também elementos referentes à oralidade, tais como, a entonação, a pausa, a intensidade e o ritmo, os quais são recuperados na escrita por meio dos sinais de pontuação.

Na próxima seção, apresentaremos os passos que trilhamos para cumprir os objetivos desta pesquisa.

\section{Contexto de realização da pesquisa}

Nesta seção, apresentaremos o contexto de produção da intervenção pedagógica que foi implementada: o local e público-alvo desta pesquisa e as etapas que compõem a intervenção desenvolvida.

Como dito, os alunos do Ensino Fundamental, em geral, estão concluindo esta etapa de ensino sem desenvolverem as habilidades necessárias para alcançar um nível adequado quanto ao uso/função dos sinais de pontuação em suas produções escritas e sem reconhecê-los como marcadores prosódicos da fala na leitura, nem como indicadores semânticos. Com a finalidade de sanar, ou, ao menos, dirimir tais dificuldades, buscamos elaborar um trabalho que contribuísse significativamente para o aprendizado dos alunos, que pudesse ser utilizado por outros professores de Língua Portuguesa e que contemplasse o que é exigido no programa de mestrado Profissional em Letras ProfLetras, a saber, um trabalho de intervenção em sala de aula.

Considerando que buscamos compreender a complexidade e os detalhes das informações daquilo que subjaz às dificuldades das turmas pesquisadas a partir dos percentuais de erros/acertos aferidos em cada atividade proposta aos dois grupos pesquisados, podemos classificar essa pesquisa como de natureza quali-quantitativa. Numa pesquisa dessa natureza, podemos mesclar os métodos qualitativo e quantitativo de análises: partir de dados numéricos, estatísticos robustos para entender e descrever uma realidade.

Esta proposta de intervenção foi elaborada em três etapas: Atividade Diagnóstica, Proposta Pedagógica com atividades e discussões sobre a pontuação, a partir de pressupostos, tais como, os postos na seção anterior deste artigo e, por fim, a Atividade Avaliativa Final.

Selecionamos duas turmas do Ensino Fundamental Anos Finais, de uma escola municipal, localizada em Vitória da Conquista, Bahia, para participarem desta pesquisa, ambas de $6^{\circ}$ ano, contendo 35 alunos cada. Em sorteio, definimos qual turma comporia o GT, que participaria de todas as etapas da pesquisa e qual turma seria considerada o GC, que não seria submetida à sequência de oficinas. 
A seleção dessas turmas decorreu do fato de a pesquisadora ser professora de Língua Portuguesa das duas classes em questão, o que viabilizou a implementação da Proposta de Intervenção Pedagógica.

Apesar de não haver obrigatoriedade de participação nas atividades, todos os alunos, após serem apresentados à proposta desta pesquisa, se dispuseram a contribuir com o desenvolvimento deste trabalho. Essa pesquisa teve aprovação do Conselho de Ética (CAAE: 54770716.3.0000.0055) e os responsáveis legais pelos estudantes assinaram o Termo de Consentimento Livre e Esclarecido (TCLE) e os estudantes assinaram o Termo de Assentimento (TA).

\section{Atividade diagnóstica e atividade avaliativa final}

As atividades que compreendem a primeira e a última partes da intervenção - Atividade Diagnóstica e Atividade Avaliativa Final - foram elaboradas e aplicadas pela própria pesquisadora durante as aulas de Língua Portuguesa na sala de aula de cada turma. Estas atividades compunham-se de duas partes: a) resolução de questões relativas aos usos e funções dos sinais de pontuação; e b) produção textual livre com vistas a avaliar de que forma os alunos empregam esses sinais em suas produções.

A realização da Atividade Diagnóstica teve como propósito fazer um levantamento do que os alunos já sabiam acerca do uso dos sinais de pontuação, bem como dos principais problemas apresentados por eles ao empregarem esses sinais, e ainda, avaliar a natureza desses problemas antes de aplicar as atividades pedagógicas.

Já a Atividade Avaliativa Final foi realizada com o objetivo de aferir os efeitos gerados com a implementação das atividades realizadas nas oficinas da Proposta Pedagógica, bem como avaliar a viabilidade desta intervenção.

As questões ${ }^{5}$ elaboradas para compor a primeira parte destas atividades foram pensadas com os seguintes objetivos: a) avaliar se os alunos conseguiriam recuperar a pontuação de um texto com base nas entonações realizadas durante a leitura oral; e b) avaliar a percepção dos alunos quanto à importância dos sinais de pontuação na atribuição/ construção de sentido do texto.

5 A primeira parte destas atividades é composta por oito questões. No entanto, apresentaremos, neste artigo, os resultados de apenas duas questões. 
Para realizar a segunda parte desta atividade, propusemos aos alunos que produzissem um texto sobre a preservação do meio ambiente e sua importância para a vida no planeta ${ }^{6}$, a fim de verificarmos de que forma os alunos usavam a pontuação em produções livres. Sugerimos aos alunos que eles criassem uma história, narrando de que forma salvariam o mundo com a ajuda de um amigo. Dada a necessidade de sabermos se os alunos sabiam ou não usar os sinais de pontuação, quais os mais frequentes, bem como, quais consistiam em maior dificuldade para os alunos, deixamos claro que eles deveriam utilizar os sinais de pontuação em seus textos.

\section{Implementação da proposta pedagógica: as oficinas}

Considerando a relevância dos sinais de pontuação para a produção escrita, para a atribuição/construção de sentido do texto, bem como para a realização de uma leitura sem infração à pontuação e, ainda, o fato de avaliarmos por meio da Atividade Diagnóstica que os alunos do sexto ano do Ensino Fundamental ainda não dominam o uso/função desses sinais, buscamos elaborar uma proposta pedagógica direcionada a esses alunos.

A elaboração desta proposta teve como objetivo proporcionar aos alunos um ensino/ aprendizado que considerasse não apenas as prescrições de regras para o uso da pontuação, mas, principalmente, que conduzisse a reflexões acerca das diferentes possibilidades de uso/função dos sinais de pontuação, considerando seus aspectos prosódicos e semânticos, de modo que passem a usá-los corretamente em suas produções escritas e que os reconheçam enquanto marcadores prosódicos da fala durante a leitura, percebendo-os como recurso que contribui para a organização e a construção/atribuição de sentido do texto.

Destacamos que esta proposta pedagógica teve como base propostas elaboradas e implementadas por Oliveira (2015) e Alves (2016), egressas do Mestrado Profissional em Letras. Assim como essas autoras, elaboramos uma sequência composta por oficinas e algumas das atividades que utilizamos também foram utilizadas por elas em suas pesquisas. Optamos por tomá-las como base em virtude dos resultados positivos obtidos pelas autoras e por considerar que o formato de oficina proporciona uma maior interação entre alunos/professor e entre alunos/alunos, o que facilita a construção do conhecimento.

Ao elaborarmos esta proposta, buscamos selecionar atividades que despertassem o interesse do aluno em relação aos sinais de pontuação, levando-o a fazer uso/emprego desses sinais em suas produções textuais e a perceber a importância da função exercida por eles na escrita em geral. Ao mesmo tempo, buscamos atividades que envolvessem

6 A escolha do tema foi baseada em uma temática que já vinha sendo trabalhada em um projeto da escola. 
a prática de leitura em voz alta, realizada tanto pelos alunos quanto pelo professoraplicador, para que os estudantes notassem a relevância em se respeitar a presença de um sinal de pontuação, produzindo a entonação adequada suscitada por este sinal.

As oficinas foram realizadas durante as aulas de Língua Portuguesa e contaram com a participação dos alunos do GT. Estas oficinas foram implementadas em seis encontros com uma duração de 100 minutos cada.

Em cumprimento à terceira etapa da Proposta de Intervenção e com o propósito de avaliar os efeitos resultantes da implementação das atividades que compunham as oficinas, aplicamos a Atividade Avaliativa Final, contendo as mesmas questões executadas quando da realização da Atividade Diagnóstica. A seguir, passaremos à análise do desempenho dos grupos teste e controle ao efetuá-las. Ademais, faremos uma análise contrastando os dados a fim de observarmos que efeitos a Proposta Pedagógica gerou para o grupo teste.

\section{Efeitos resultantes da implementação da proposta pedagógica}

Com vistas a observar os efeitos resultantes da aplicação da Proposta Pedagógica para os alunos que compõem o GT, analisamos os dados apresentados por este grupo nos estágios anterior e posterior à implementação desta proposta, bem como em contraste com os dados apresentados pelo GC. Conforme já exposto, a pesquisa tem natureza quali-quantitativa, de forma que expomos os nossos dados através de uma estatística descritiva, para, a partir da sua sumarização, interpretá-los de forma a buscar compreender qual a natureza da dificuldade dos discentes e em que medida a intervenção proposta contribuiu para dirimir a dificuldade deles, no que tange à pontuação. Além disso, também nos valemos de uma análise qualitativa sobretudo no que se refere à análise dos textos escritos pelos alunos participantes.

No intuito de avaliar se os alunos conseguiriam recuperar a pontuação de um texto com base nas entonações suscitadas durante a leitura oral, solicitamos que eles pontuassem o texto - conforme apresentado no quadro 1 - considerando as entonações realizadas pelo professor-aplicador no ato da leitura oral.

Quadro 1. Texto utilizado para realização da questão referente à relação existente entre os sinais de pontuação e a entonação

\section{Que medo!}

Minha mãe ouviu um barulho de noite!

Quando ela olhou (sinal 1) tinha um homem embaixo da cama (sinal 2) 
(sinal 3) Era um ladrão (sinal 4)

(sinal 5) Que nada (sinal 6) era meu pai (sinal 7) Ele também tinha ouvido o barulho

Fonte: Adaptado de http://inep.gov.br/educacao_basica

Os resultados alcançados nesta questão são bastante expressivos. No momento da aplicação da Atividade Diagnóstica, consoante o gráfico 1, registraram-se quatro itens com percentuais de acerto abaixo da média, o sinal $1($,), o sinal 4 (?) o sinal $6($, ) e o sinal 7 (!) e um item (o sinal 2 (!)) com o índice de acerto pouco acima da média, 51\%. Por sua vez, no momento da aplicação da Atividade Avaliativa Final, o GT elevou os percentuais de acerto de todos os itens, com índices variando entre 51\% e 91\%.

Gráfico 1. Índices de acerto, por aluno, registrados pelo GT na questão referente à relação existente entre os sinais de pontuação e a entonação - atividades Diagnóstica e Avaliativa Final

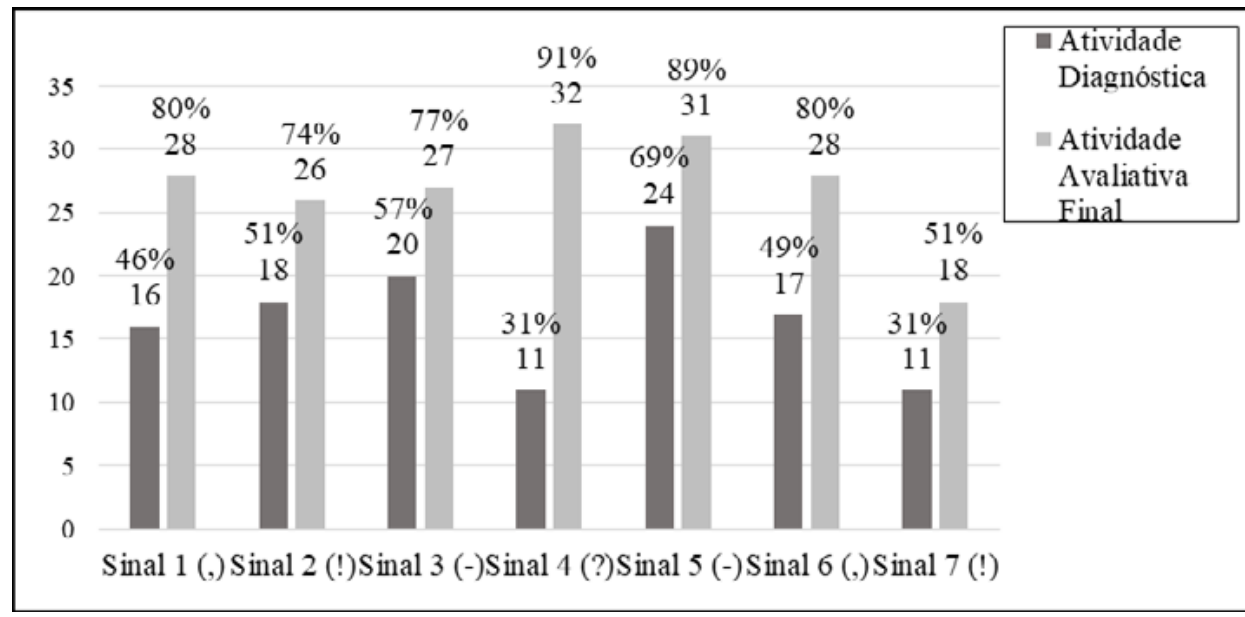

Fonte: Elaboração própria

Tais resultados tão animadores apontam para o êxito alcançado com a implementação da Proposta Pedagógica, pois, ao resolverem essa questão na última atividade, os alunos do GT mostraram-se mais atentos aos aspectos entoacionais gerados pelos sinais de pontuação a partir da leitura de um texto, os quais foram abordados durante o desenvolvimento da sequência de oficinas. Essa abordagem foi realizada com base em estudos realizados por Pacheco (2003, p. 108), cujos resultados mostraram que há "uma correspondência entre a intenção do leitor de produzir um determinado marcador e a percepção do ouvinte, levando este a ouvir e a representar esse marcador como tal.".

Em se tratando do desempenho do GC nesta mesma questão, observamos que este grupo não alcançou um bom desempenho, conforme ilustrado no gráfico 2. 
Gráfico 2. Índices de acerto, por aluno, registrados pelo GC na questão referente à relação existente entre os sinais de pontuação e a entonação - atividades Diagnóstica e Avaliativa Final

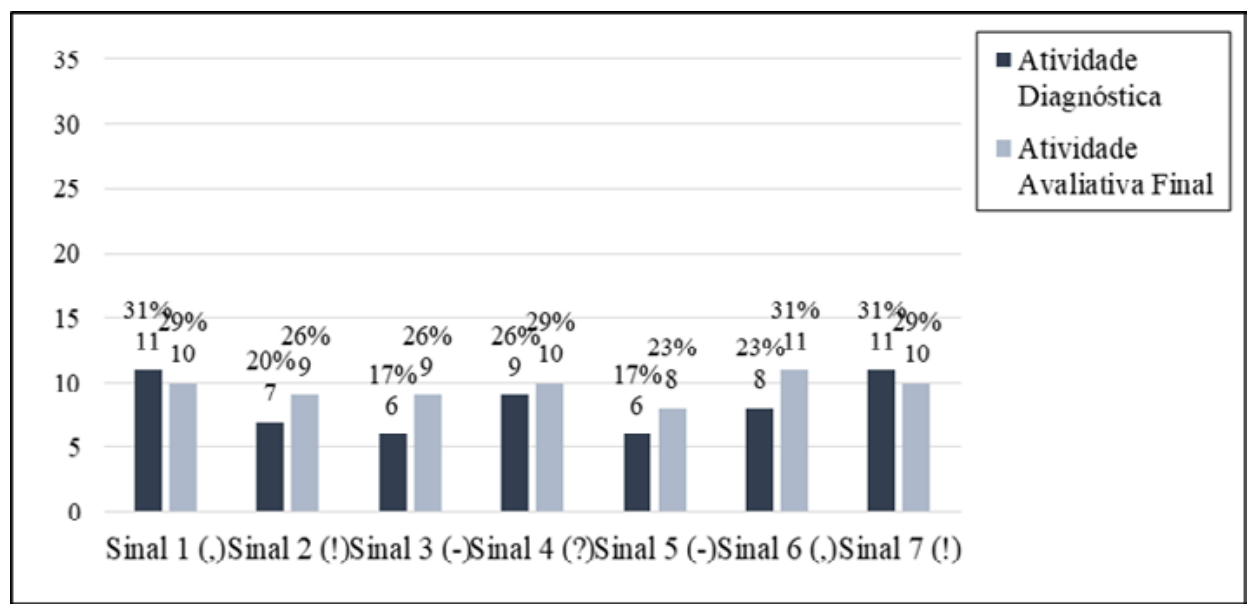

Fonte: Elaboração própria

Observamos que, contrastando os índices de acerto alcançados na primeira atividade e os que foram registrados na segunda, este grupo apresentou um aumento sutil em cinco dos sete itens em análise. No entanto, vale ressaltar que em nenhum dos itens avaliados houve alcance de 50\% por parte dos alunos. Estes resultados demonstram a pouca habilidade dos alunos em perceberem os aspectos entoacionais suscitados, durante a leitura oral, pela pontuação presente no texto, ou seja, esses alunos não percebem ainda as variações decorrentes da oralização do sinal de pontuação (PACHECO, 2003).

Isto corrobora a ideia de que o ensino/aprendizado dos sinais de pontuação não deve estar pautado apenas em regras sintáticas, mas sobretudo deve lançar mão das informações prosódicas que cada sinal de pontuação carrega. Assim, ler em voz alta e ouvir leituras orais são atos de suma importância para que o aluno tenha consciência da presença dessas informações e passe a percebê-las como suporte na utilização dos sinais de pontuação, pois, segundo Pacheco (2003), a prática de leitura em voz alta faz com que o aluno/ouvinte perceba as variações melódicas decorrentes da presença dos sinais de pontuação. Acreditamos que a consciência do papel da pontuação na leitura em voz alta pode auxiliar na recuperação desses sinais na leitura silenciosa, o que favorece o entendimento do texto.

A seguir, apresentamos a questão elaborada com o objetivo de avaliar a percepção dos alunos quanto à importância dos sinais de pontuação na atribuição/construção de sentido. Nesta questão, os alunos deveriam pontuar as frases (apresentadas no quadro 2), utilizando vírgulas, de modo a atender a sugestão de sentido que estava descrita entre parênteses. 
Quadro 2. Frases que integram a questão referente à relação entre pontuação e sentido

a) A humanidade testemunhará o fim não haverá salvação. (A humanidade será extinta)

b) A humanidade testemunhará o fim não haverá salvação. (A humanidade será salva)

c) Não seja rápido. (A pessoa precisa se apressar)

d) Não seja rápido. (A pessoa pode agir devagar)

Fonte: Elaboração própria

Como podemos observar no gráfico 3, ao resolverem essa questão pela primeira vez, o GT apresentou índices muito abaixo da média dos 50\%, variando entre $20 \%$ e $26 \%$. Já na resolução da segunda atividade, o grupo avançou para índices bastante satisfatórios, todos os itens superaram a média de 50\%: 54\% (frase a), 57\% (frase b), 77\% (frase c) e $63 \%$ (frase d).

Gráfico 3. Índices de acerto, por aluno, registrados pelo GT na questão referente à relação entre pontuação e sentido - atividades Diagnóstica e Avaliativa Final

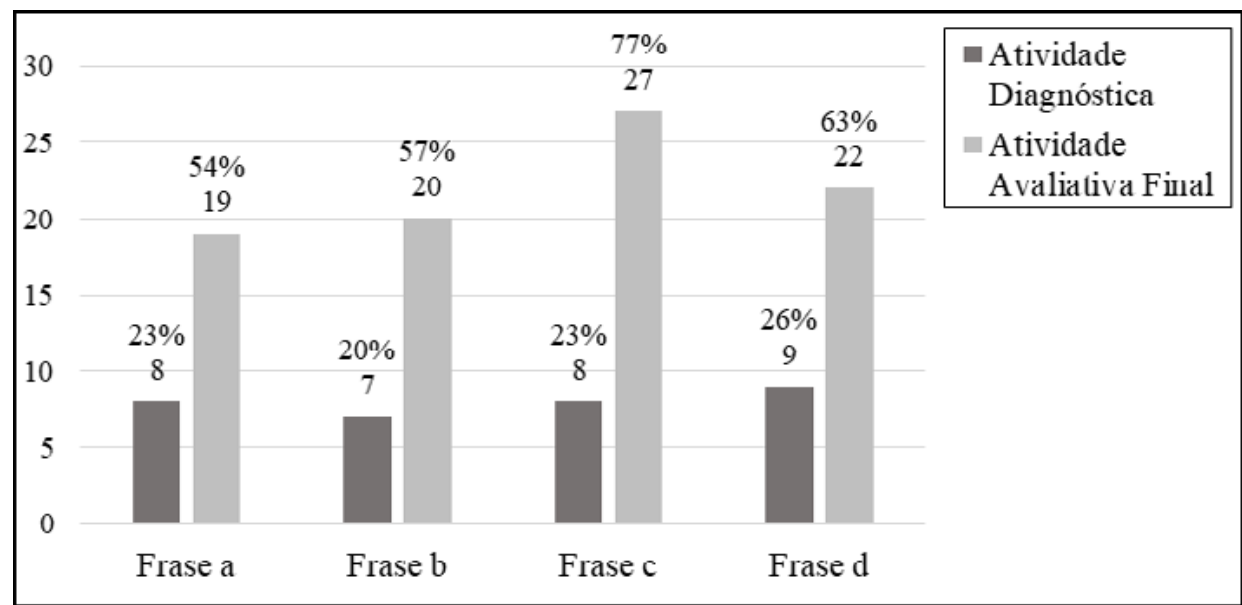

Fonte: Elaboração própria

Os dados resultantes da execução desta questão evidenciam que as discussões em torno da temática pontuação e sentido, embasadas nos pressupostos de Cagliari (1999, p. 198) que apresenta os "sinais semânticos-discursivos", os quais exercem a função de evitar as ambiguidades e, ainda, no que defende Pacheco (2003, p. 60), que "a presença de um sinal de pontuação em um texto é mais que uma questão de estilo, pois ele sinaliza variações prosódicas que trazem sentido para o texto", auxiliaram os alunos a sistematizar a importante relação existente entre o uso adequado dos sinais de pontuação e a atribuição/construção/mutação de sentidos do texto. 
O GC, por sua vez, apresentou um resultado pouco expressivo em todas as etapas realizadas. De acordo com a ilustração do gráfıco 4, na primeira etapa os índices variaram entre $0 \%$ e $2 \%$. Já na segunda etapa, os índices variaram entre $2 \%$ e 14\%.

Gráfico 4. Índices de acerto, por aluno, registrados pelo GC na questão referente à relação entre pontuação e sentido - atividades Diagnóstica e Avaliativa Final

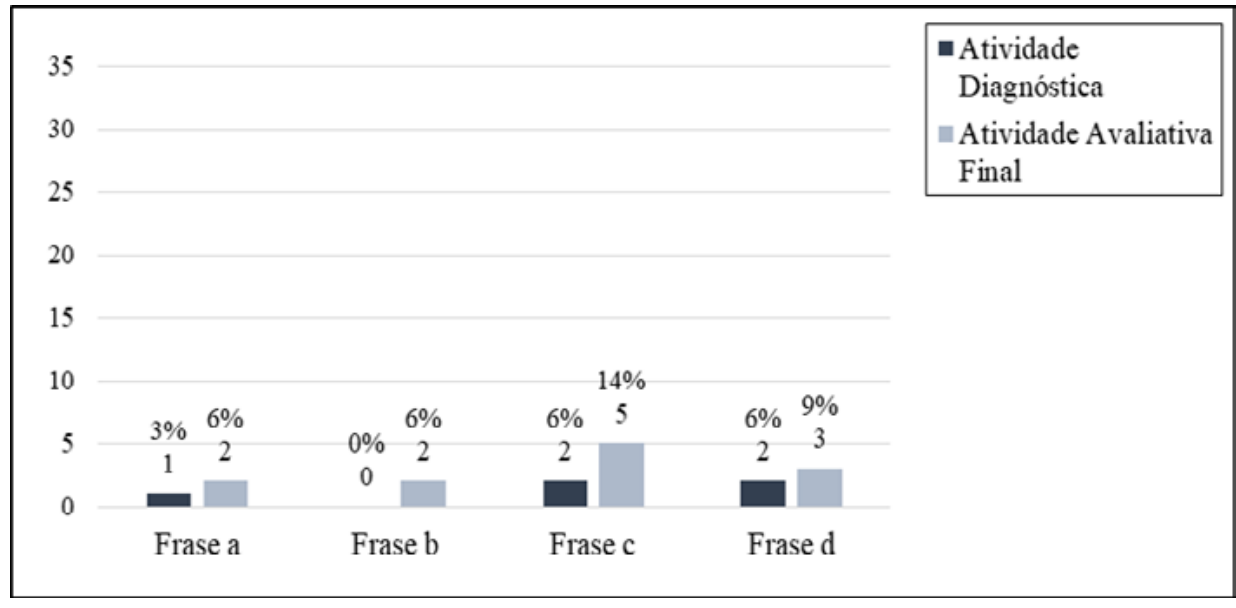

Fonte: Elaboração própria

Embora tenha registrado índices maiores, quando da realização da Atividade Avaliativa Final, os alunos participantes deste grupo ainda não sistematizaram a importante relação existente entre o emprego adequado dos sinais de pontuação e a atribuição/ construção/mutação de sentidos do texto e ainda não percebem que o fato de inserir ou mudar uma vírgula de posição dentro de um enunciado acarretará mudança tanto no padrão prosódico quanto no efeito semântico.

Em relação às produções escritas, verificamos, por meio dos dados resultantes da aplicação da segunda parte da Atividade Diagnóstica, que a maioria dos alunos dos dois grupos apresentava dificuldade em empregar os sinais de pontuação em seus textos. Por outro lado, após a implementação da Proposta Pedagógica, por meio das oficinas, foi possível constatar que houve um avanço no desempenho do GT com relação ao uso dos sinais de pontuação. Ao passo que os alunos do GC continuaram a produzir textos com ausência total ou parcial desses sinais, os alunos do GT passaram a pontuar os seus textos com mais cuidado, demonstrando ter adquirido conhecimentos referentes aos usos e funções dos sinais de pontuação, conforme podemos verificar nos exemplos a seguir.

Os textos (1) e (2), produzidos antes da implementação das oficinas, mostram que esses alunos do GT empregaram apenas o ponto final (.) para encerrá-los, não apresentando, assim, as marcações de pausas e entonações, que guiariam o leitor no ato da leitura. 
Textos produzidos dessa forma, sem os sinais de pontuação, dificultam o entendimento do leitor, que se apoia na pontuação do texto para atribuir-Ihe sentido (CHACON, 1996).

1. "Eu e minha amiga kaiza estavamos passeando pela praça e um cavalo estava passando pela estrada e eu e minha amiga fomos ajuda-lo a tira ele da estrada e bota na praça para ele passa pela praça e depois uma senhora que estava perdida pedido ajuda e fomos leva ela até sua casa ela pediu muito obrigada meninas espero encontra pessoas como vocês." (Aluno $A^{7}-G T$ )

2. "era uma vez eu e minho amige foi fazer uma aventura na floresto o lo nés se divertimos muito batante e agente fez até pequi nicqui no furesto e ai Nós plantamos varias coisas e brincamos bastante." ( Aluno B - GT)

Já nos exemplos (3) e (4), observamos que é nítido o avanço no desenvolvimento desses alunos. Tanto o aluno "A" quanto o aluno "B" utilizaram o ponto (.) para encerrar devidamente os períodos. Ambos utilizaram os dois pontos (:), sendo que em (3) este sinal introduz a fala de uma personagem e em (4) ele indica uma enumeração de fatos. A vírgula (,) também foi empregada pelos dois alunos: o aluno " $\mathrm{A}$ " a utilizou para isolar os adjuntos adverbiais e o aluno " $\mathrm{B}$ ", para separar fatos que aparecem em sequência e para isolar uma expressão explicativa.

3. "Sofia e Kaiza estavam indo na sorveteria e no meio do caminho elas encontraram muitos lixos. Daí, elas falaram uma com a outra:

- Vamos catar esses lixos para salvar nosso planeta terra. Para não poluir mas do que tá poluído. Quando elas terminaram de catar o lixo, elas voltaram para lavar a mão e voltar para a sorveteria. Quando elas terminaram, foram para casa brincar um pouco." (Aluno $\left.A-G T, L^{8} \cdot 1-10\right)$

4. "Bom, na minha opinião, nós temos que parar de jogar lixos nas ruas e parar de queimar as plantas. Dicas: para agente não sofrer com as poluições nós temos que jogar os lixos no lixo, não deixar água acumulada nas ruas e também não queimar matos." (Aluno B - GT, L. 2-7)

Ao compararmos os exemplos dos textos produzidos pelos alunos "A" e "B", do GT, na Atividade Avaliativa Final àqueles produzidos na Atividade Diagnóstica, verificamos que os alunos, em geral, demonstraram ter assimilado os conceitos relacionados aos usos e

7 Utilizaremos as letras maiúsculas, em ordem alfabética, para nos referirmos aos alunos produtores dos textos em análise.

8 A letra L em maiúscula indica as linhas no texto original do aluno. 
funções dos sinais de pontuação, bem como a importante relação entre esses sinais e a organização e clareza do texto.

Outro fato bastante recorrente nos textos produzidos na Atividade Diagnóstica foi o emprego indiscriminado de vírgulas, ora em excesso, onde não cabia pontuar, ora em lugar de outro sinal.

No exemplo (5) - Atividade Diagnóstica -, o aluno "C" emprega a vírgula (,) de forma desnecessária, separando elementos que se complementam, em quatro momentos: linhas 1, 2 e 5. Em outro momento, na linha 1, após o termo "natureza", o aluno emprega este sinal no lugar em que deveria conter um ponto (.) para encerrar o período. Vale destacar também que há vários períodos soltos, sem qualquer tipo de pontuação que os delimite.

5. "Eu queria fazer uma viagem, pela natureza, eu chamei uma amiga, minha e fui chegando lá eu já olhei e gostei, da natureza é incrível ai eu andei, andei, andei quando cheguei no meio da natureza, as árvores estavam todas caídas, as flores muchas as folhas mucha eu falei com minha, amiga." (Aluno C - GT, L. 12-14)

Por outro lado, observamos a inserção adequada de vírgulas para separar elementos repetidos, linha 3. Este acerto pode estar relacionado ao fato de que há uma proximidade entre esse uso da vírgula (,) e o padrão entonacional da fala, uma vez que este sinal está indicando uma pausa que também seria realizada na oralidade. Assim, podemos dizer que, ao indicar essa pausa, o aluno "C" transpôs, "para o texto escrito, um retrato fiel da fala." (CAGLIARI, 1999, p. 201).

Em (6) - Atividade Avaliativa Final -, verificamos que o aluno inseriu corretamente as vírgulas nas linhas 1 e 2, empregando-as para isolar um adjunto adverbial. Já nas linhas 3 e 5, este sinal foi empregado para separar elementos de mesmo valor sintático. Ressaltamos que ocorreu o emprego de outros sinais de pontuação, por parte do aluno " $\mathrm{C}$ ", os dois pontos (:), na linha 2, indicando uma enumeração de fatos e na linha 3 para indicar a fala de uma personagem; o travessão $(-)$, na linha 4, introduzindo a fala de uma personagem; a exclamação (!), linha 4, que pode suscitar diferentes entonações, variando de acordo com o conhecimento prévio dos interlocutores ou indicando uma afırmativa mais enfática, conforme Cagliari (1999). A análise do contexto em que o sinal de interrogação foi inserido, em (6), sugere que a entonação a ser realizada é a de uma afirmativa com ênfase; por fim, o aluno empregou o sinal de interrogação (?), o qual suscita uma entonação interrogativa. 
6. "Eu fui acampar com a minha melhor amiga e, quando chegamos lá, vimos como tava a situação da natureza: algumas árvores cortadas, caídas no chão, as flores muchas. E eu disse assim pra ela:

- Olha como estão as árvores, olha as flores todas muchas! E agora?" (Aluno C - GT, L. 1-5)

Este avanço no desempenho dos alunos, observado nas produções realizadas na Atividade Avaliativa Final, reflete a forma como abordamos o estudo deste sinal ao desenvolvermos a Proposta Pedagógica: considerando seu aspecto sintático, uma vez que delimita classes e unidades sintáticas; seu aspecto prosódico, pois é um sinal indicativo de pausa, que sinaliza para o leitor que entonação será suscitada no ato da leitura; e seu aspecto semântico, visto que também interfere na produção/atribuição de sentido do texto, delimitando unidades que vão além da frase, conforme Cagliari (1999).

Por outro lado, os alunos do GC não demonstraram grande avanço em suas produções escritas, continuaram apresentando dificuldades quanto ao emprego dos sinais de pontuação, inserindo-os em suas produções de forma equivocada, consoante os exemplos (7) e (8), a seguir.

7. "Quando as pessoas jogavam lixo No chão Ela falava assim Ei Moço Não joga lixo no chão aí o Mosso falou: desculpa eu vou joga No lixo" (Aluno D - GC, L. 3-6)

8. "Reciclam pouca gente recicla mais muitas gentes não reciclam tem uma menina que ela fala pegos essa garrafa e decoro mais tem muita gente que não decora ele jogam no chão" (Aluno D - GC, L. 1-4)

Nos trechos (7) e (8), notamos que o aluno "D" não utilizou nenhum sinal de pontuação, nem para marcar as pausas e entonações e nem para marcar a mudança de turnos conversacionais no discurso direto. O texto produzido na Atividade Avaliativa Final, trecho (8), é bastante semelhante ao que o aluno produziu na Atividade Diagnóstica, trecho (7), ambos se apresentam sem praticamente nenhuma pontuação. Na primeira atividade o aluno empregou apenas os dois pontos (:) em determinado momento do texto, já na última o aluno utilizou apenas o ponto final (.) para encerrar o texto.

Produções como as representadas em (7) e em (8) não fornecem ao leitor os subsídios necessários para a realização de uma boa leitura, visto que, de acordo com Cagliari (1989), os sinais de pontuação que trazem para o enunciado indicações de diferentes variações melódicas, para a orientação do leitor no ato efetivo de leitura, estão ausentes. 
Nos trechos (9) e (10), a seguir, notamos um avanço sutil do aluno "E", componente do GC. Em (9), produção realizada na Atividade Diagnóstica, houve o emprego do ponto final (.) em substituição ao ponto de interrogação (?), linha 1, e de uma vírgula (,) em lugar de um ponto final (.) para encerrar o período, linha 2. Observamos ainda que o aluno " $E$ " deixou de empregar vírgula (,) tanto para isolar o vocativo e o adjunto adverbial, linha 1, quanto para separar a oração adversativa, linha 3. Também não ocorreu o emprego de sinais de pontuação que marcassem a troca dos turnos conversacionais, sugeridos na linha 1.

9. "Amiga vamos colocar aquelas latas de lixo. Ok. Daí elas fizeram um vídeo que os pais ajudaram, depois esse vídeo ficou muito famoso e todos começaram a cuidar mas um grupo de 4 pessoas não cuidaram" (Aluno E - GC, L. 4-8)

10. "Assim vamos ter um mundo melhor, vamos cuidar da natureza? Como? É muito simples basta você reciclar coisas que duram anos" (Aluno E - GC, L. 4-6)

Já em (10), texto produzido na Atividade Avaliativa Final, percebemos que alguns problemas se repetem como a ausência de marcação do discurso direto, de vírgula (,) para isolar os adjuntos adverbiais, linhas 1 e 2, e também o emprego da vírgula para encerrar o período, linha 1. Por outro lado, notamos que o aluno " $E$ " utilizou os sinais de interrogação (?) de forma correta, linhas 1 e 2, diferentemente do que fizera em sua produção anterior.

De modo geral, as produções apresentadas pelo GC sugerem que os alunos componentes deste grupo ainda não sistematizaram a importante relação entre os sinais de pontuação e a organização e clareza do texto, visto que a presença/ausência destes sinais não sugere uma preocupação do produtor do texto em sinalizar para o leitor de que forma ele deverá se comportar ao ler tal produção.

Vale ressaltar que verificamos também alguns textos, produzidos pelo GC, com ausência total de sinais de pontuação e outros com o emprego apenas do ponto final (.) para encerrar o texto. Isto demonstra que os alunos deste grupo ainda não conseguem empregar adequadamente e pontuação e assim demonstrar a relevante contribuição desses sinais para a organização e clareza do texto. A ausência dessas marcas gráficas compromete, em certa medida, o entendimento do texto, uma vez que "a pontuação retrata certa teoria sobre um texto e, sobretudo, como ele se divide em partes, implicando significados sintáticos e textuais importantes." (CAGLIARI, 1999, p. 197).

Desta forma, entendemos que a Proposta Pedagógica teve efeito bastante positivo no aumento do nível de domínio quanto ao uso dos sinais de pontuação por parte do 
GT. É possível afirmar que esse efeito foi constatado na compreensão e emprego da pontuação tanto no que se refere aos aspectos sintáticos dos sinais de pontuação, como considerando seu papel de marcador prosódico, uma vez que eles não são "meras marcas gráficas, eles são pistas prosódicas importantes para a leitura." (PACHECO, 2003, p. 109). E, ainda, considerando que estes sinais corroboram para que se estabeleçam a organização e os efeitos de sentido do texto. Nota-se, portanto, a importância de se dar à pontuação o status que esse conteúdo requer, visto que muitas vezes ele fica relegado a segundo plano nas salas de aula, bem como é necessário que esse ensino seja pautado em estudos que considerem os aspectos linguísticos que estão na base da pontuação, como marcador prosódico e como informação importante na recuperação de informações sintáticas e de sentido do texto. É pela consciência desses aspectos que o aluno vai pontuar corretamente o seu texto e não por ter decorado uma série de regras quanto ao seu emprego.

\section{Considerações finais}

Ao analisarmos os resultados apresentados pelos dois grupos, observamos que houve um avanço do grupo teste, pois este grupo apresentou, em todas as questões da Atividade Avaliativa Final, índices de acerto superiores aos que foram apresentados quando da realização da Atividade Diagnóstica, o que já era expectável, visto que apenas os alunos componentes deste grupo foram submetidos à Proposta Pedagógica. Por sua vez, o GC apresentou, praticamente, os mesmos índices de acerto registrados quando da aplicação da primeira atividade, com pequenos aumentos nos índices de acerto em algumas questões.

Em relação às produções escritas, notamos que, mais uma vez, o grupo teste avançou. Ao passo que os alunos deste grupo produziram textos, pontuando-os com mais cautela, de forma correta, demonstrando ter adquirido conhecimentos referentes ao uso e funções dos sinais de pontuação, os alunos do GC continuaram a produzir textos com ausência total ou parcial dos sinais de pontuação, o que demonstra a dificuldade que esses alunos ainda apresentam em empregar os sinais de pontuação de forma adequada em suas produções.

Quando contrastamos os dados obtidos pelo grupo teste nas duas etapas, observamos um avanço significativo no desempenho dos alunos que compunham este grupo. Verificamos que ocorreu um aumento nos índices de acerto em todas as questões propostas nessa atividade, mostrando que os alunos participantes deste grupo assimilaram bem os conceitos referentes aos sinais de pontuação que foram trabalhados ao longo do desenvolvimento da Proposta Pedagógica.

Os dados resultantes das produções escritas também evidenciam que os alunos componentes do grupo teste, após participarem das discussões sobre o conteúdo durante 
a realização das oficinas, passaram a ter mais atenção ao produzir textos/enunciados, empregando os sinais de pontuação de forma mais adequada, considerando que estes sinais funcionam como recursos que orientam o leitor durante a leitura.

A partir dos dados resultantes da aplicação da Atividade Avaliativa Final, verificamos que os alunos do grupo teste já conseguem: a) reconhecer algumas funções dos sinais de pontuação, relacionando-as às marcas gráficas referentes a esses sinais; b) sistematizar a importante relação existente entre o uso adequado dos sinais de pontuação e a atribuição/ construção/mutação de sentidos do texto; c) perceber as entonações suscitadas pela presença de um sinal de pontuação durante a realização da leitura oral; e d) produzir textos mais organizados e mais claros, empregando de modo mais adequado os sinais de pontuação em suas produções, sinalizando para o leitor quais são as entonações a serem suscitadas.

Considerando os resultados positivos alcançados pelos participantes do grupo teste na execução da Atividade Avaliativa Final e a confirmação das nossas hipóteses, a Proposta Pedagógica implementada é, de fato, relevante. Desta forma, acreditamos que a proposta desenvolvida se constitui como um recurso que tem muito a contribuir com o fazer pedagógico de outros professores de Língua Portuguesa acerca do ensino dos sinais de pontuação considerando seus aspectos sintáticos, semânticos e prosódicos, uma vez que foi elaborada em moldes que permitem a sua aplicação em contextos diferentes, desde que se façam os ajustes necessários. Diante disso, retificamos que se trata de uma proposta que pode ser replicada nas escolas, especialmente em classes com o mesmo perfil dos estudantes por nós pesquisados.

\section{REFERÊNCIAS}

ALVES, D. L. R. Leitura e escrita: o papel dos marcadores prosódicos na compreensão. 2016. Dissertação (Mestrado Profissional em Letras) - Universidade Estadual do Sudoeste da Bahia, Vitória da Conquista, 2016.

BRASIL. Base Nacional Comum Curricular (BNCC): A Educação é a Base - MEC. 2018.

BRASIL. Brasil no PISA 2015: análises e reflexões sobre o desempenho dos estudantes brasileiros/OCDE - Organização para a Cooperação e Desenvolvimento Econômico. São Paulo: Fundação Santillana, 2016.

BRASIL. Instituto Nacional de Estudos e Pesquisas Educacionais Anísio Teixeira. Escalas de Proficiência. Disponível em: http://provabrasil.inep.gov.br. Acesso em: 19 nov. 2018. 
BRASIL. Secretaria de Educação Fundamental. Parâmetros Curriculares Nacionais: terceiro e quarto ciclos do ensino fundamental: introdução aos parâmetros curriculares nacionais/ Secretaria de Educação Fundamental. Brasília: MEC/SEF, 1998.

CAGLIARI, L. C. Breve história dos sinais de pontuação. In: MASSINI-CAGLIARI, G.; CAGLIARI, L. C. Diante das letras: a escrita na alfabetização. Campinas: Mercado das Letras, 1999.

CAGLIARI, L. C. Marcadores prosódicos na escrita. In: SEMINÁRIO DO GRUPO DE ESTUDOS LINGUÍSTICOS, 18, 1989, Lorena. Anais... Lorena: Grupo de Estudos Linguísticos de São Paulo, 1989. p. 195-203.

CHACON, L. Ritmo da escrita: uma organização do heterogêneo da linguagem. 1996. Tese (Doutorado em Linguística) - Instituto de Estudos da Linguagem, Universidade Estadual de Campinas, Campinas, 1996.

OLIVEIRA, E. S. de A. Os sinais de pontuação e a representação de aspectos prosódicos na escrita e na leitura de alunos do nono ano do Ensino Fundamental. 2015. Dissertação (Mestrado Profissional em Letras) - Universidade Estadual do Sudoeste da Bahia, Vitória da Conquista, 2015.

PACHECO, V. Investigação fonético-acústico e experimental dos sinais de pontuação enquanto marcadores prosódicos. 2003. Dissertação (Mestrado em Linguística) - Instituto de Estudos da Linguagem, Universidade Estadual de Campinas, Campinas, 2003.

PACHECO, V. O efeito dos estímulos auditivo e visual na percepção de marcadores prosódicos lexicais e gráficos usados na escrita do Português do Brasil. 2006. Tese (Doutorado em Linguística) - Instituto de Estudos da Linguagem, Universidade Estadual de Campinas, Campinas, 2006. 